\title{
Physical activity, nutritional status, and dietary habits of students of a medical university
}

\author{
Bogna Grygiel-Górniak ${ }^{1,2}$ • Andrzej Tomczak ${ }^{3}$ - Natalia Krulikowska ${ }^{2}$. \\ Juliusz Przysławski $^{2}$ - Agnieszka Seraszek-Jaros ${ }^{4}$. Elżbieta Kaczmarek ${ }^{4}$
}

Received: 15 February 2016/Accepted: 20 May 2016/Published online: 13 June 2016

(C) The Author(s) 2016. This article is published with open access at Springerlink.com

\begin{abstract}
Nutritional habits and physical activity influence the health status of young adults. In this study, we engaged a group of 151 students from a medical university (90 female and 61 male subjects). Anthropometric parameters, dietary habits (a 7-day dietary recall), and level of physical activity were measured. It was found that the daily food rations of female (F) and male (M) students were improperly balanced and characterized by high amount of total and animal protein, phosphorus, vitamin A, cholesterol, and insufficient intake of carbohydrates, dietary fiber, and vitamin C. Female subjects consumed low amounts of total fat and calcium. The intake of protein (total and animal), fat, phosphorus, and cholesterol correlated with higher body mass. The physical activity of the students was found to be higher than the average physical activity of the European Union populations, and a general tendency of lowering level of physical activity with age was observed. Students with the highest level of physical activity (MET > 1500) consumed lower amounts of simple carbohydrates (galactose and saccharose) when compared to students with lower physical activity (MET $<600$, $p<0.05)$. Therefore, this study concluded that the dietary habits should be modified to prevent the development of
\end{abstract}

Bogna Grygiel-Górniak

bgrygiel@ump.edu.pl

1 Department of Rheumatology and Internal Diseases, Poznan University of Medical Sciences, Poznań, Poland

2 Department of Bromatology and Human Nutrition, Poznan University of Medical Sciences, Poznań, Poland

3 Józef Piłsudski University of Physical Education in Warsaw, Faculty in Biała Podlaska, Biała Podlaska, Poland

4 Department of Bioinformatics and Computational Biology, Poznan University of Medical Sciences, Poznań, Poland diet-dependent diseases. Various forms of physical activity should be proposed to students and they should be encouraged to participate in high level of physical activity so as to promote good health status.

Keywords Nutritional habits of students - Anthropometric measurement IPAQ

\section{Introduction}

Recently, many studies have suggested that lifestyle changes in adolescents and young adults are necessary because of the increased tendency of various adverse health outcomes not otherwise typical for their age, including hypertension, dyslipidemia, and metabolic syndromes [1]. Proper dietary behavior and adequate physical activities reduce the risks of the aforementioned diseases. Many recent studies have underlined the risks of excessive energy intake and sedentary lifestyle in young adults, which can be associated with the increased prevalence of dyslipidemia, obesity, and cardiovascular diseases (CVD) [2]. Particularly, sedentary lifestyle (e.g., playing computer games) is associated with unhealthy snacking patterns, including low intake of fruits and vegetables and overconsumption of energy and fat $[2,3]$. Because the level of physical activity influences on physical condition, health status, and quality of life, it is important to undertake physical activity of different intensities until the age of 25-30 to maximize the development of motor skills and physical fitness $[4,5]$. However, these recommendations are poorly realized. Taking into consideration the abovementioned criteria, in our study, we attempted to estimate the relationship between nutritional status, dietary habits, and level of physical activity in a group of women and men studying at 
the Faculty of Pharmacy at Poznan University of Medical Sciences focusing on the prophylaxis of non-communicable diseases such as dyslipidemia, obesity, and osteoporosis.

\section{Experimental procedures}

In this study, 151 students participated from the Pharmacy Faculty of Medical University. All students signed a written consent form. Basic anthropometrical measurements including body mass, height, and waist and hip circumferences were measured; height and waist and hip circumferences were measured using a flexible measuring tape (measurement precision $0.1 \mathrm{~cm}$ ) and body mass was weighed using a professional body-weight measuring machine (measurement precision $0.1 \mathrm{~kg}$, SECA device). Body mass index was calculated as weight/height squared $\left(\mathrm{kg} / \mathrm{m}^{2}\right)$ and waist-to-hip ratio (WHR) as the proportion of waist-to-hip circumferences [6]. The Bodystat 1500 analyzer (BIA method) was used to analyze the body composition of the students (including body fat and lean body mass with measurement precision $0.1 \%$ of total body mass). Because hydration/dehydration processes influence on bioelectrical impedance results, all students were instructed to keep a normal diet and to avoid strenuous exercises for minimum of 3 days before body composition measurement. Students underwent test procedures between 8.00 and 9.30 am in a state of normal hydration (no exercise or alcohol/caffeine consumption in the preceding $12 \mathrm{~h}$ and no eating or drinking in the preceding 3-4 h).

The food intake was assessed by the method of 24-h dietary recall of 7 days [7]. Each participant was trained by a dietician and the participants were instructed in detail on what portions have to be consumed and how to record them (they were instructed to weigh every servings and record it; moreover, a special table with the amount of portions to be consumed and a colored nutritional atlas representing the portion sizes of various servings were also used to make the analysis more accurate). All selfreported dietary records were checked and analyzed by the dietician and every questionable recording was once again evaluated together with the students. The results of the questionnaire were analyzed using computer databases stored in Microsoft Access 2000 [8], which were prepared on the basis of the tables of composition and nutrition value of food products [9]. The energy and nutrients intake recommended by the National Food and Nutrition Institute, Warsaw, was considered as a scale to determine the degree to which the recommended energy and nutrients intakes were met [10]. As culinary processes such as boiling decrease the vitamin content, the values expected to be met for vitamin intakes were reduced and are as follows: $25 \%$ for vitamin A, $30 \%$ for vitamin $\mathrm{E}$, and $55 \%$ for vitamin $\mathrm{C}$. The cholesterol and dietary fiber intakes were compared with nutritional prophylaxis recommendation ( $300 \mathrm{mg} /$ day and $27-42 \mathrm{~g} /$ day, respectively) [11]. Because of different recommendations of nutrient intake for $\mathrm{F}$ and $\mathrm{M}$, norm realization (NR) was calculated for both groups (Fig. 1). A non-parametric Kruskal-Wallis ANOVA and multiple comparisons of $z^{\prime}$ values were performed to examine the galactose and saccharose intake in the three groups with different physical activity at a significance level of $\alpha=0.05$. The level of physical activity was assessed by the International Physical

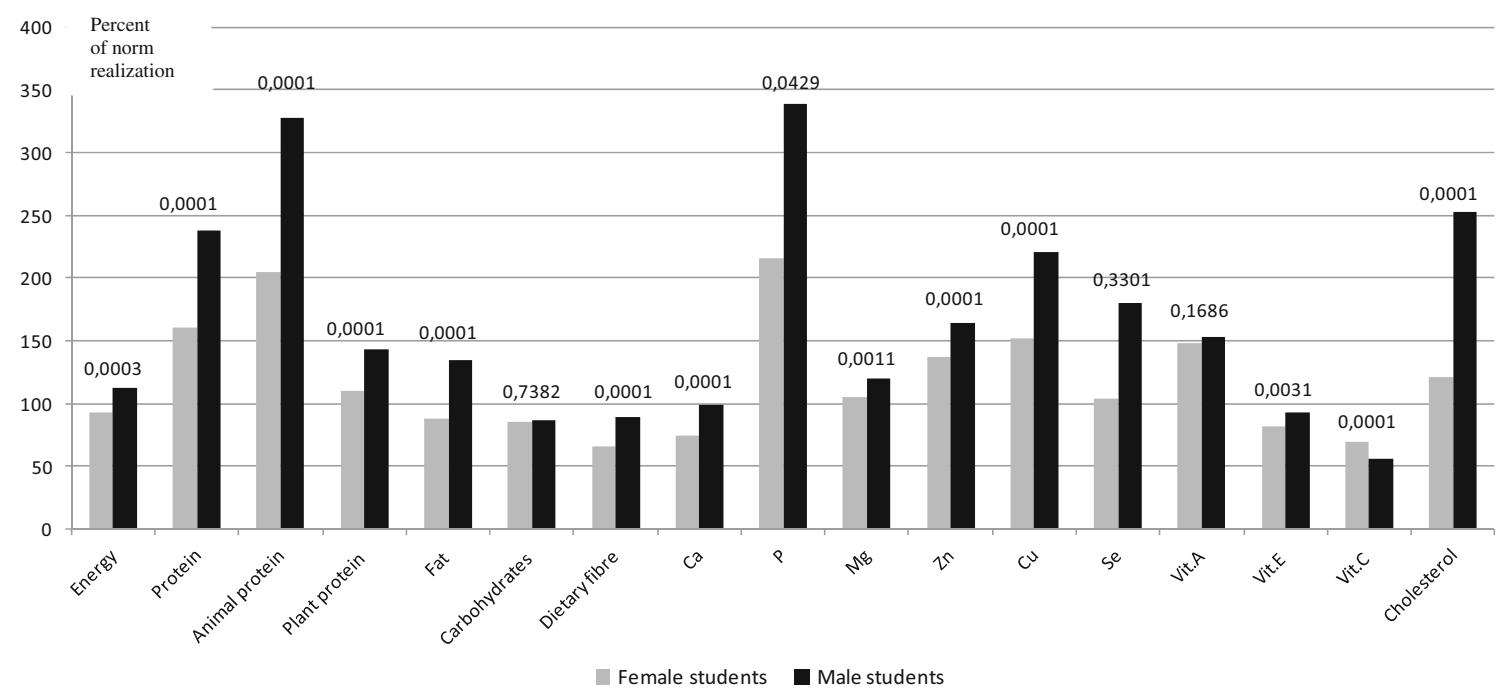

Fig. 1 The degree of norm realization on recommended level and nutritional recommendation for energy and select dietary components in female and male group of students in the aspect of cardiovascular diseases prophylaxis. $C a$ calcium, $P$ phosphorus, $M g$ magnesium, $Z n$ zinc, $C u$ copper, $S e$ selenium, Vit.A vitamin A, Vit.E vitamin E, Vit.C vitamin $\mathrm{C}$ 
Activity Questionnaire (IPAQ) [12], widely used in Polish population among different age groups characterized by divers education levels and occupations [13, 14]. Generally, in the group with lower physical activity, the individuals took fewer than $600 \mathrm{MET} \cdot \mathrm{min} /$ week; in those with sufficient (moderate) physical activity, 600-1500 MET·min/week; and in those with higher physical activity, more than $1500 \mathrm{MET} \cdot \mathrm{min} /$ week. Besides physical activity, the intensity and frequency of effort during the week were also assessed [12].

\section{Results}

The age of both female and male groups was similar, but other parameters such as height, body mass, waist circumference, body mass index (BMI), and percent of body fat were determined based on gender (Table 1). The values of waist circumference were within the recommended range and did not exceed $88 \mathrm{~cm}$ in F and $102 \mathrm{~cm}$ in M [15]. In both genders, the values of waist circumference and WHR were within the health limits (F: WHR $<0.85$ and M: WHR $<1.0$ ).

The energy intake was lower than the recommended values in females and higher in males (Fig. 1). Both the protein intake and the percentage of energy from protein were higher than the recommended values in both groups. The consumption of animal protein was two times higher than the recommended values in $\mathrm{F}$ and three times higher in $\mathrm{M}$ (Fig. 1) and that of fat was lower in F (88.5\%NR) and higher in M (132\%NR). The consumption of carbohydrates and dietary fiber did not fulfill the dietary recommendations (27-40 g/day) in both groups (Table 1; Fig. 1). The amounts of galactose, lactose, maltose, saccharose, and starch were higher in $\mathrm{M}$ than in $\mathrm{F}$ (Table 1). The starch intake was $60.1 \%$ of the total carbohydrates intake in $\mathrm{F}$ and $65.6 \%$ in $\mathrm{M}$, whereas saccharose consumption was $16.8 \%$ of the total carbohydrates in $\mathrm{F}$ and $14 \%$ in $\mathrm{M}$ (data not shown in the table). The average content of dietary cholesterol exceeded the dietary recommendations (300 $\mathrm{mg} /$ day) and was tow times higher in $\mathrm{M}(p=0.0001)$.

The intake of macro- and microelements fulfilled or even exceeded the recommended values (Table 1), with the exception of calcium in F, which was only $74.5 \% \mathrm{NR}$ (Fig. 1). The intake of phosphorus was twofold higher than the recommended value in $\mathrm{F}$ and threefold higher in $\mathrm{M}$, and the intake of vitamin A was higher than the estimated average requirement (EAR). Consumption of vitamin $\mathrm{C}$ was lower than the recommended value in both groups and vitamin $\mathrm{E}$ was found to be lower in the female group. We also found that the intake of protein (total and animal), fat, phosphorus, and cholesterol correlated with higher body mass (Table 1).

According to the IPAQ criteria, of all respondents, nearly $43 \%$ revealed a high level of physical activity, $45.0 \%$ moderate, and $12.0 \%$ low (Table 2). The percent of women with high and sufficient physical activity was higher than that of men. The detailed analysis of physical activity showed that in the leisure time (recreation and sports), about $61.2 \%$ of respondents undertook intensive physical activity, $31.8 \%$ moderate, and $72.0 \%$ preferred walking (data not shown in tables). As their daily activity, nearly $18.6 \%$ of all respondents performed intensive physical activity, $29.4 \%$ moderate physical activity, and $47.3 \%$ preferred walking. These data showed that students, who participated in sports, usually were involved in intense physical activity, but during recreation time, they preferred light-to-moderate activity such as walking or cycling. In weekdays, nearly $46.0 \%$ of students were observed sitting for more than $6 \mathrm{~h}$ daily, while in weekends, nearly $40.3 \%$ of all responders were observed sitting. Results obtained by ANOVA revealed that students with higher level of physical activity consumed lower amount of simple carbohydrates such as galactose and saccharose (Table 3).

\section{Discussions}

Anthropometrical parameters revealed similar age, proper body mass, and BMI values. The results of the body fat content obtained in this study were comparable to that of other studies [16, 17]. The distribution of fat and the values of waist circumference were within the recommended range and thus did not indicate an increased cardio-diabetological risk [15]. Although the use of bioelectrical impendence (BIA) for research is questioned because of its high degree of variability, it is commonly used in many researches [18-20]. Moreover, recent data have shown that BIA methods can also be used in the measurement of other physiopathological conditions like inflammation, hydration, or cell infiltration of fat [18]. Besides this, the measurements made by BODYSTAT 1500 (BIA device) are more accurate than those obtained using the dual frequency BIA device [19] and it is commonly used in many research studies [18-20].

Data analysis of students' dietary habits showed an improperly balanced daily food rations (DFR) (Table 1). The energy consumption was lower than the recommended values in women and higher in men (88.5 vs $132 \% \mathrm{NR}$, $p=0.0003$ ) (Fig. 1). This might be due to the fact that young female subjects usually have a tendency to reduce their energy intake to look thinner, have a tendency to overestimate their weight, and more often reveal an improper body image perception [21].

In both groups, overconsumption of protein was observed and intake of animal protein dominated over the intake of plant protein and this was significantly higher in M (Table 1; Fig. 1). The prospective cohort studies or 
Table 1 Anthropometric and nutritional characterization of pharmacy students

\begin{tabular}{|c|c|c|c|}
\hline Analyzed parameters & $\begin{array}{l}\text { Female students } \\
N=90 \\
X \pm \text { SD }\end{array}$ & $\begin{array}{l}\text { Male students } \\
N=61 \\
X \pm \mathrm{SD}\end{array}$ & $p$ value \\
\hline Age (years) & $23.0 \pm 0.1$ & $23.1 \pm 0.2$ & 0.6565 \\
\hline Height (cm) & $167.2 \pm 0.5$ & $182.0 \pm 0.9$ & 0.0001 \\
\hline Body mass (kg) & $59.5 \pm 0.8$ & $80.1 \pm 1.4$ & 0.0001 \\
\hline BMI $\left(\mathrm{kg} / \mathrm{m}^{2}\right)$ & $21.2 \pm 0.3$ & $24.2 \pm 0.4$ & 0.0001 \\
\hline Waist circumference $(\mathrm{cm})$ & $71.9 \pm 0.8$ & $86.5 \pm 1.2$ & 0.0001 \\
\hline Hip circumference $(\mathrm{cm})$ & $96.1 \pm 0.7$ & $98.3 \pm 1.1$ & 0.0842 \\
\hline WHR & $0.81 \pm 0.06$ & $0.88 \pm 0.01$ & 0.5003 \\
\hline Body fat (\% body mass) & $27.6 \pm 4.2$ & $19.3 \pm 3.6$ & 0.0001 \\
\hline Energy (kcal) & $1846.5 \pm 42.8$ & $2878.2 \pm 124.3$ & 0.0001 \\
\hline Protein $(\mathrm{g})$ & $73.8 \pm 1.9$ & $121.0 \pm 5.7$ & 0.0001 \\
\hline Animal protein (g) & $47.0 \pm 1.5$ & $83.5 \pm 4.7$ & 0.0001 \\
\hline Plant protein $(\mathrm{g})$ & $25.2 \pm 0.7$ & $36.5 \pm 1.8$ & 0.0001 \\
\hline Fat $(\mathrm{g})$ & $66.4 \pm 1.9$ & $114.5 \pm 6.3$ & 0.0001 \\
\hline Carbohydrates (g) & $243.2 \pm 5.8$ & $343.0 \pm 14.3$ & 0.0001 \\
\hline Protein (\% energy) & $16.2 \pm 0.3$ & $17.1 \pm 0.4$ & 0.1025 \\
\hline Fat (\% energy) & $31.5 \pm 0.4$ & $35.3 \pm 0.7$ & 0.0001 \\
\hline Carbohydrates (\% energy) & $53.3 \pm 0.5$ & $47.9 \pm 0.8$ & 0.0001 \\
\hline Dietary fiber (g) & $19.7 \pm 0.6$ & $26.7 \pm 1.3$ & 0.0001 \\
\hline Glucose $(\mathrm{g})$ & $6.76 \pm 0.4$ & $7.69 \pm 0.7$ & 0.1913 \\
\hline Fructose (g) & $8.37 \pm 0.46$ & $9.69 \pm 1.02$ & 0.1729 \\
\hline Galactose (g) & $0,66 \pm 0,06$ & $0,87 \pm 0,17$ & 0.0421 \\
\hline Lactose (g) & $9.69 \pm 0.43$ & $12.22 \pm 1.08$ & 0.0092 \\
\hline Maltose (g) & $0.13 \pm 0.01$ & $0.21 \pm 0.02$ & 0.0001 \\
\hline Saccharose $(\mathrm{g})$ & $40.89 \pm 1.86$ & $48.74 \pm 3.52$ & 0.0362 \\
\hline Starch $(g)$ & $146.26 \pm 4.34$ & $228.80 \pm 10.43$ & 0.0001 \\
\hline Cholesterol (mg) & $364.2 \pm 15.3$ & $758.8 \pm 50.7$ & 0.0001 \\
\hline Calcium (mg) & $744.9 \pm 31.23$ & $969.6 \pm 53.85$ & 0.0002 \\
\hline Phosphorus (mg) & $1257.5 \pm 36.3$ & $1911.8 \pm 98.9$ & 0.0001 \\
\hline Magnesium (mg) & $271.4 \pm 7.8$ & $385.0 \pm 20.4$ & 0.0001 \\
\hline Zinc (mg) & $9.37 \pm 0.32$ & $15.02 \pm 0.73$ & 0.0001 \\
\hline Copper (mg) & $1.07 \pm 0.03$ & $1.51 \pm 0.08$ & 0.0001 \\
\hline Selenium $(\mu \mathrm{g})$ & $47.04 \pm 4.42$ & $78.89 \pm 3.60$ & 0.0001 \\
\hline Vitamin A $(\mu \mathrm{g})$ & $739.5 \pm 54.9$ & $985.5 \pm 79.2$ & 0.0002 \\
\hline Vitamin E (mg) & $6.48 \pm 0.37$ & $9.32 \pm 0.91$ & 0.0001 \\
\hline Vitamin C (mg) & $42.41 \pm 3.92$ & $47.90 \pm 9.42$ & 0.5481 \\
\hline \multicolumn{4}{|l|}{ Spearman correlation $n=151$} \\
\hline Analyzed parameter & $\mathrm{R}$-Spearman & $t(N-2)$ & $p$ value \\
\hline Protein $(\mathrm{g})$ and body mass $(\mathrm{kg})$ & 0.5959 & 9.0583 & 0.0001 \\
\hline Animal protein $(\mathrm{g})$ and body mass $(\mathrm{kg})$ & 0.5997 & 9.1488 & 0.0001 \\
\hline Fat $(\mathrm{g})$ and body mass $(\mathrm{kg})$ & 0.5005 & 7.0575 & 0.0001 \\
\hline Phosphorus (mg) and body mass (kg) & 0.5642 & 8.3425 & 0.0001 \\
\hline Cholesterol (mg) and body mass (kg) & 0.5339 & 7.7091 & 0.0001 \\
\hline
\end{tabular}

$B M I$ body mass index, WHR waist to hip ratio, $X$ arithmetic mean, $S D$ standard deviation, $n$ number of women 
Table 2 Levels of physical activity examined by criteria IPAQ

\begin{tabular}{lllr}
\hline Variables & \multicolumn{2}{l}{ Level of physical activity } & \\
\cline { 2 - 4 } & High & Sufficient \\
& MET $>1500$ & $68(45.0 \%)$ & \multicolumn{1}{l}{ Low } \\
& $65(43.0 \%)$ & $41(45.6 \%)$ & $18(12.0 \%)$ \\
\hline The respondents $(n=151)$ & $40(44.4 \%)$ & $25(41.0 \%)$ & $9(10.0 \%)$ \\
Women $(n=90)$ & $22(36.0 \%)$ & & $14(23.0 \%)$ \\
Men $(n=61)$ & &
\end{tabular}

Table 3 The relation between physical activity and consumption of simple carbohydrates in the group of students

\begin{tabular}{lllll}
\hline Dietary component & $\begin{array}{l}\text { Value of MET } \\
(\text { MET } \cdot \mathrm{min} / \text { week })\end{array}$ & $n$ (both F and M) & $\begin{array}{l}\text { Dietary intake }(\mathrm{g}) \\
X \pm \mathrm{SD}\end{array}$ & $p$ value \\
\hline Galaktoza & MET $<600$ & 33 & $0.43 \pm 0.08$ & $* 0.0248$ \\
& MET $=601-1500$ & 63 & $0.28 \pm 0.06$ & $* * 0.0478$ \\
& MET $>1500$ & 55 & $0.23 \pm 0.06$ & (between MET $<600$ and MET $>1500)$ \\
Sacharoza & MET $<600$ & 33 & $52.56 \pm 3.96$ & $* 0.0098$ \\
& MET $=601-1500$ & 63 & $40.22 \pm 2.11$ & $* * 0.0174$ (between MET $<600$ and MET 600-1500) \\
& MET $>1500$ & 55 & $40.35 \pm 2.97$ & $* * 0.0173$ (between MET $<600$ and MET $>1500)$ \\
\hline
\end{tabular}

$* p$ value of Kruskal-Wallis test, ${ }^{* *} p$ value of multiple comparisons test

randomized controlled trials conducted so far underline the supportive influence of protein on bone health [22, 23], and high protein products such as dairy products are also an important source of dietary calcium [24]. However, high amount of protein intake may increase urinary excretion of calcium and decrease bone density showing deleterious effects in early adulthood. This effect is potentiated, particularly, if calcium intake is insufficient [16]. In our study, female students consumed high amount of protein and low quantity of calcium and thus they are at a risk of developing osteoporosis.

An increased intake of fat was observed in male group, but the BMI value was found to be normal, which indicates a high physical activity in this group. In both groups, the percentage of energy obtained from carbohydrates was low and did not reach a minimum of $55 \%$ of energy (most of them should have been derived from polysaccharides) [11]. The intake of all simple carbohydrates (glucose, fructose, galactose, lactose, maltose, and saccharose) was high, whereas the intake of dietary fiber was low. Dietary fiber reveals a positive influence on intestine peristalsis, and the fraction of beta-glucans alters serum lipid profile in a beneficial way [25]. The amount of this component to be consumed should be increased in the DFR of the analyzed groups, as cholesterol intake in these groups was found to be higher than the recommended value and exceeded $300 \mathrm{mg} /$ day.

Intake of selected elements is important for good health status (e.g., bone condition) of young adults [26]. Low intake of calcium in the female group is a risk factor for low bone mineral density, especially when peak bone mass is reached in early adulthood (by the age of 30) [26, 27]. The absorption of calcium depends on the intake of phosphorous. Unfortunately, we observed a high intake of phosphorus in both groups, which exceeded the recommended level and was much higher in male subjects. Indeed, phosphorus is a principal structural element of bone in the form of calcium phosphate salt called hydroxyapatite, but its high dietary intake may contribute to dietary acid load (referred as the renal acid load) and causes bone demineralization [28, 29].

An alarming low intake of vitamins $\mathrm{C}$ in both groups and vitamin $\mathrm{E}$ in female group was observed (Table 1; Fig. 1). Vitamin $C$ is an antioxidant, which interacts with vitamin $\mathrm{E}$ by reducing the tocopheroxyl radical and thus regenerates its native tocopherol [30]. It also enhances intestinal absorption of iron by reducing iron from ferric to ferrous form [31].

Not only the dietary habits but also physical activity influence health (including bone condition) status [27, 32]. In this study, the physical activity of students was higher (Table 2) when compared to the activity during professional duty in Polish population $(18.6 \%$ intensive and $29.4 \%$ moderate) [33]. The analysis of MET value (assessed by IPAQ) showed that $43.0 \%$ of all respondents revealed a high level of physical activity (Table 2), which is higher than in the Polish population $(33.5 \%)$ and European Union $(31.3 \%)$ population [33, 34], but lower when compared to school adolescents (girls- $67.7 \%$ and boys- $-76.2 \%$ ) [13]. These data show a general trend of lowering level of physical activity with age. Nearly $12.0 \%$ of $\mathrm{F}$ and $\mathrm{M}$ students showed low levels of physical activity 
(low activity is observed in $27.9 \%$ of Polish and $31.0 \%$ of European populations) $[33,34]$. This might be probably due to the fact that pharmacy students have a wider knowledge in disease prevention and healthy lifestyle when compared to the normal population.

In this study, we observed an interesting relationship between physical activity and consumption of simple carbohydrates (Table 3). Groups with the highest level of physical activity consumed lower levels of simple carbohydrates (galactose and saccharose) $(p<0.05)$ compared to students with lower level of physical activity. We assume that students with higher physical activity paid more attention to dietary choices and avoided products with high amount of simple sugars.

\section{Conclusions}

This study found that the DFR of F and M students were improperly balanced. The intake of protein (total and animal), fat, phosphorus, and cholesterol correlated with higher body mass. Therefore, it is important to modify the dietary habits of students and monitor them so as to prevent them from the risk of developing dyslipidemia, obesity, or osteoporosis in the future. The study also found that the physical activity of the $\mathrm{F}$ and $\mathrm{M}$ students was higher than the average physical activity of the Polish adults. Subjects with higher level of physical activity consumed lower amounts of simple carbohydrates. In conclusion, this study emphasizes that various forms of physical activity should be implemented in the schedule of students and they should be encouraged to participate in a high level of physical activity so as to promote good health status.

\section{Compliance with ethical standards}

Conflict of interest The authors have declared no conflict of interest.

Ethical standard All procedures performed in studies involving human participants were in accordance with the ethical standards of the institutional and/or national research committee and with the 1964 Helsinki declaration and its later amendments or comparable ethical standards.

Informed consent All of the subjects provided written consent to participate in the study, after the study procedure and methods were explained to them.

Open Access This article is distributed under the terms of the Creative Commons Attribution 4.0 International License (http://crea tivecommons.org/licenses/by/4.0/), which permits unrestricted use, distribution, and reproduction in any medium, provided you give appropriate credit to the original author(s) and the source, provide a link to the Creative Commons license, and indicate if changes were made.

\section{References}

1. Anthony D, George P, Eaton CB (2014) American College of Cardiology/American Heart Association; Eighth Joint National Committee Cardiac risk factors: new cholesterol and blood pressure management guidelines. FP Essent 421:28-43

2. Chapman CD, Nilsson VC, Thune HÅ, Cedernaes J, Le Grevès M, Hogenkamp PS, Benedict C, Schiöth HB (2014) Watching TV and food intake: the role of content. PLoS One 9:e100602

3. Ganesh JS, Rao YY, Ravikumar R, Jayakrishnan GA, Iwasaki M, Preethy S, Abraham SJ (2014) Beneficial effects of black yeast derived 1-3, 1-6 Beta Glucan-Nichi Glucan in a dyslipidemic individual of Indian origin-a case report. J Diet Suppl 11(1): $1-6$

4. Blair S, Cheng Y, Holder J (2001) Is physical activity or physical fitness more important in defining health benefits? Med Sci Sports Exerc 33(6 Suppl):S379-S399

5. Chakravarthy M, Joyner MJ, Booth FW (2002) An obligation for primary care physicians to prescribe physical activity to sedentary patients to reduce the risk of chronic health conditions. Mayo Clin Proc 77(2):165-173

6. World Health Organization (WHO) (2003) Diet, nutrition and the prevention of chronic diseases. In: WHO technical report series 916, chapter 5, Geneva

7. Charzewska $J$ (1998) Instruction of the dietary recall gathering from the last $24 \mathrm{~h}$. Press National Food and Nutrition Institute, Warsaw (in Polish)

8. Przysławski J, Walkowiak J, Gertig H, Cichy W, Gajewska B (1998) Nutritional value of daily food rations (DFR's) taken by cystic fibrosis children. Pediatr Pol 73:399-405

9. Kunachowicz H, Nadolna I, Przygoda B, Iwanow K (1998) Tables of nutritious value of food products. Press National Food and Nutrition Institute, Warsaw (in Polish)

10. Jarosz M, Bułhak-Jachymczyk B (2013) Recommended values of human nutrition., The background of obesity and non-communicable diseases preventionMedical Publishing Company PZWL, Warsaw (in Polish)

11. WHO (2007) Diet, nutrition Protein and Amino Acid Requirements in Human Nutrition. In: Report of a Joint WHO/FAO/UNU Expert Consultation. Technical reports series 935. WHO, Geneva

12. Biernat E, Stupnicki R, Lebiedziński B, Janczewska L (2008) Assessment of physical activity by applying IPAQ questionnaire. Phys Educ Sport 52:46-52

13. Bergier B, Bergier J, Paprzycki P (2014) Level and determinants of physical activity among school adolescents in Poland. Ann Agric Environ Med 21(1):75-83

14. Tomczak A (2012) Physical activity of soldiers in the Polish Armed Force's military administration units and special units. Biomed Hum Kinet 4:93-97

15. Expert Panel on Detection, Evaluation, and Treatment of High Blood Cholesterol in Adults (2001) Executive summary of the third report of The National Cholesterol Education Program (NCEP) expert panel on detection, evaluation, and treatment of high blood cholesterol in adults (adult treatment panel III). JAMA 285(19):2486-2497

16. Heaney RP, Nordin BE (2002) Calcium effects on phosphorus absorption: implications for the prevention and co-therapy of osteoporosis. J Am Coll Nutr 21(3):239-244

17. Olszanecka-Glinianowicz M, Madej P, Zdun D, BożentowiczWikarek M, Sikora J, Chudek J, Skałba P (2012) Are plasma levels of visfatin and retinol-binding protein 4 (RBP4) associated with body mass, metabolic and hormonal disturbances in women with polycystic ovary syndrome? Eur J Obstet Gynecol Reprod Biol 162(1):55-61 
18. Větrovská R, Vilikus Z, Klaschka J, Stránská Z, Svačina Š, Svobodová Š, Matoulek M (2014) Does impedance measure a functional state of the body fat? Physiol Res 63(Suppl 2):S309S 320

19. Simpson JA, Lobo DN, Anderson JA, Macdonald IA, Perkins AC, Neal KR, Allison SP, Rowlands BJ (2001) Body water compartment measurements: a comparison of bioelectrical impedance analysis with tritium and sodium bromide dilution techniques. Clin Nutr 20(4):339-343

20. Datta Banik S, Andrade Olalde AC, Rodriguez L, Dickinson F (2014) The effect of socioeconomic indicators and macronutrient intake rate on body composition in adolescents 12-16 years old in Merida, Yucatan. Anthropol Anz 71(4):347-368

21. Zaccagni L, Masotti S, Donati R, Mazzoni G, Gualdi-Russo E (2014) Body image and weight perceptions in relation to actual measurements by means of a new index and level of physical activity in Italian university students. J Transl Med 12:42

22. Munger RG, Cerhan JR, Chiu BC (1999) Prospective study of dietary protein intake and risk of hip fracture in postmenopausal women. Am J Clin Nutr 69(1):147-152

23. Schurch MA, Rizzoli R, Slosman D, Vadas L, Vergnaud P, Bonjour JP (1998) Protein supplements increase serum insulinlike growth factor-I levels and attenuate proximal femur bone loss in patients with recent hip fracture. A randomized doubleblind placebo-controlled trial. Ann Intern Med 128(10):801-809

24. Johnson-Down L, Ritter H, Starkey LJ, Gray-Donald K (2006) Primary food sources of nutrients in the diet of Canadian adults. Can J Diet Pract Res 67(1):7-13

25. Gunes FE, Bekiroglu N, Imeryuz N, Agirbasli M (2012) Relation between eating habits and a high body mass index among freshman students: a cross-sectional study. J Am Coll Nutr 31(3): $167-174$

26. Anderson JJ (2001) Calcium requirements during adolescence to maximize bone health. J Am Coll Nutr 20(2 Suppl):186S-191S

27. Ilich JZ, Kerstetter JE (2000) Nutrition in bone health revisited: a story beyond calcium. J Am Coll Nutr 19(6):715-737

28. New SA (2002) Nutrition Society Medal lecture. The role of the skeleton in acid-base homeostasis. Proc Nutr Soc 2002(61):151-164

29. Remer T, Manz F (1995) Potential renal acid load of foods and its influence on urine pH. J Am Diet Assoc 95(7):791-797

30. Carr AC, Vissers MC (2013) Synthetic or food-derived vitamin C-are they equally bioavailable? Nutrients 5(11):4284-4304

31. Gropper SS, Smith JL, Groff JL (2009) Advanced nutrition and human metabolism, 5th edn. Wadsworth, Belmont

32. Hoelscher DM, Barroso C, Springer A, Castrucci B, Kelder SH (2009) Prevalence of self-reported activity and sedentary behaviors among 4th-, 8th-, and 11th-grade Texas public school children: the school physical activity and nutrition study. J Phys Act Health 6(5):535-547

33. Piątkowska M (2010) Participation of Poles in physical activity compared to other countries of the European Union. In: Modern methods of research activity, fitness and human performance. AWF Warsaw, University of Physical Education Jozef Pilsudski (in Polish)

34. Sjöström M, Oja P, Hagstromer $M$, Smith BJ, Bauman A (2006) Health-en-hancing physical activity across European Union countries: the Eurobarometer study. J Public Health 14:291-300 